\title{
Rhein protects against cerebral ischemic-/reperfusion-induced oxidative stress and apoptosis in rats
}

\author{
QIPENG ZHAO ${ }^{1,2^{*}}$, XIAOBO WANG ${ }^{2,3^{*}}$, AILING CHEN $^{2}$, XIULI CHENG $^{1}$, GUOXIN ZHANG $^{1}$, \\ JIANMIN SUN ${ }^{5}$, YUNSHENG ZHAO ${ }^{6}$, YU HUANG ${ }^{6}$ and YAFEI ZHU ${ }^{1,4}$ \\ ${ }^{1}$ Key Laboratory of Hui Ethnic Medicine Modernization, Ministry of Education; ${ }^{2}$ Department of Pharmacology, \\ Ningxia Medical University, Yinchuan, Ningxia 750004; ${ }^{3}$ Department of Pharmacology, Chengdu University of TCM, \\ Chengdu, Sichuan 610075; ${ }^{4}$ Ningxia Key Laboratory of Craniocerebral Diseases of Ningxia Hui Autonomous Region; \\ ${ }^{5}$ College of Basic Medicine; and ${ }^{6}$ Ningxia Hui Modern Medicine Engineering Research Center, \\ Ningxia Medical University, Yinchuan, Ningxia 750004, P.R. China
}

Received March 10, 2017; Accepted February 8, 2018

DOI: $10.3892 / \mathrm{ijmm} .2018 .3488$

\begin{abstract}
The present study aimed to investigate the protective effects of rhein on cerebral ischemic/reperfusion (I/R) injury in rats. The present study focused on the effect of rhein on oxidative stress and apoptotic factors, which are considered to serve an important role in the onset of I/R injury. Sprague-Dawley rats were subjected to middle cerebral artery occlusion. Neurological functional scores (NFSs) were evaluated according to the Zea Longa's score criteria and the area of brain infarct was determined by triphenyltetrazolium chloride staining. The morphology of the nerve cells in the cortex was observed following hematoxylin and eosin staining. In addition, levels of oxidative stress were assessed by measuring the levels of superoxide dismutase (SOD), glutathione-peroxidase (GSH-Px), catalase (CAT) and malondialdehyde (MDA). Levels of B-cell lymphoma-2 (Bcl-2), apoptosis regulator Bax (BAX), caspase-9, caspase-3 and cleaved caspase-3 expression were analyzed using western blot analysis. Levels of caspase- 9 and caspase-3 mRNA expression were obtained using reverse transcription-quantitative polymerase chain reaction. The results revealed that treatment with 50 or $100 \mathrm{mg} / \mathrm{kg}$ rhein significantly improved the NFS and markedly attenuated the area of infarction. Rhein also significantly reduced the content of MDA and significantly increased SOD, GSH-Px and CAT
\end{abstract}

Correspondence to: Miss. Yafei Zhu, Key Laboratory of Hui Ethnic Medicine Modernization, Ministry of Education, Ningxia Medical University, 1160 Shengli Street, Yinchuan, Ningxia Hui Autonomous Region 750004, P.R. China

E-mail: 867453132@qq.com

"Contributed equally

Key words: rhein, cerebral ischemic reperfusion, oxidative stress, apoptosis, caspase-9, caspase-3, B-cell lymphoma-2, apoptosis regulator Bax activity. Western blot analysis indicated that rhein significantly decreased the expression of BAX and enhanced the expression of Bcl-2. Compared with the I/R group, levels of caspase-9, caspase-3 and cleaved caspase-3 protein expression were significantly decreased in the rhein treatment groups. Additionally, rhein treatment significantly reduced levels of caspase- 9 and caspase- 3 mRNA expression. These results suggest that rhein exhibits protective effects during cerebral I/R injury and its underlying mechanism of action may involve the inhibition of oxidative stress and apoptosis.

\section{Introduction}

Ischemic stroke is a leading cause of mortality and disability worldwide (1). Survivors typically suffer from permanent brain damage, resulting in a reduced quality of life and increased social burden (2). Cerebral blood flow reperfusion is the primary treatment option for stroke (3). However, cerebral ischemia/reperfusion (I/R) induces a series of pathophysiological processes, which may cause further damage, including I/R injury (4).

Oxidative stress and neuronal apoptosis are important factors in the pathological process of I/R injury that occurs in cerebral ischemic stroke followed by reperfusion (5). Oxidative stress refers to a comparative surplus of reactive oxygen species (ROS) caused by an imbalance between oxidants and antioxidants (6). The brain tissue is sensitive to oxidative stress as it contains low levels of endogenous antioxidant enzymes, including superoxide dismutase (SOD), glutathione-peroxidase (GSH-Px), and catalase (CAT), which act as cellular defenses against ROS (7). Malondialdehyde (MDA) is primarily induced by ROS and is commonly used as a biomarker of oxidative stress (8). Experimental and clinical studies have demonstrated that the expression of SODs, CATs and GSH-Px are significantly reduced (7,9-12) and MDA is significantly elevated in animal models of stroke and in patients that have experienced an ischemic stroke (12).

Oxidative stress is implicated in the initiation of apoptosis and it has been suggested that the balance between the 
anti-apoptotic protein B-cell lymphoma-2 (Bcl-2) and the pro-apoptotic apoptosis regulator Bax (BAX) protein regulates apoptosis (13). BAX mediates the activation of caspase-9, which is upregulated following ischemia in human brain tissue (14). In animal models of ischemic stroke, caspase-9 leads to the activation of caspase- 3 , which is considered to be a key mediator of apoptosis. Wagner et al (15) revealed that cleaved caspase-3 was predominantly associated with cellular responses to stroke and this has been supported by the results of other studies (16-18). Therefore, modulation of $\mathrm{Bcl}-2 / \mathrm{BAX}$ and the suppression of caspase-9, caspase- 3 and cleaved caspase- 3 expression may serve a protective role in the treatment of cerebral I/R injury.

Rhein is a naturally occurring anthraquinone compound isolated from Radix et Rhizoma Rhei and is involved in a number of biological activities, including the suppression of ROS, downregulation of intracellular calcium concentration, promotion of microcirculatory function, inhibition of neutrophil migration and the promotion of anti-inflammatory effects (19-22). The blood-brain barrier is disrupted during cerebral I/R injury and previous studies have revealed that segments of rhein are able to pass through the disrupted blood-brain barrier (23), inhibit cerebral infarction and improve the neurological functional score (NFS) (24). Therefore, rhein may have potential beneficial effects in anticerebral I/R injury. However, to the best of our knowledge, the signaling mechanisms that underlie the protective effects of rhein against $\mathrm{I} / \mathrm{R}$ remain unknown.

There have been few previous studies investigating the effect of rhein on cerebral I/R injury. Therefore, the present study aimed to evaluate the effects of rhein on ischemic injury, neurological outcomes, oxidative stress and apoptosis biomarkers in rats following ischemic stroke induced by middle cerebral artery occlusion (MCAO).

\section{Materials and methods}

Reagents. Rhein (molecular formula, $\mathrm{C}_{15} \mathrm{H}_{8} \mathrm{O}_{6}$; molecular weight, 284.225) was purchased from the National Institute for Food and Drug Control (Beijing, China). Nimodipine tablets were provided by Bayer AG (Leverkusen, Germany) and 2,3,5-triphenyltetrazolium chloride (TTC) was obtained from Sigma-Aldrich; Merck KGaA (Darmstadt, Germany). A Total Extraction Sample kit and a BCA protein assay kit were purchased from Nanjing KeyGen Biotech Co., Ltd. (Nanjing, China). Antibodies against caspase-9 (cat. no. ab2013), caspase-3 (cat. no. ab44976) and GAPDH (cat. no. ab9485) were obtained from Abcam (Cambridge, UK). Cleaved caspase-3 (cat. no. 9661), Bcl-2 (cat. no. 2876), BAX (cat. no. 2772) and $\beta$-actin (cat. no. 4970) antibodies were procured from Cell Signaling Technology, Inc. (Danvers, MA, USA). Horseradish peroxidase-conjugated goat anti-rabbit immunoglobulin G (cat. no. ZB-2301) was obtained from OriGene Technologies, Inc. (Beijing, China). A Total RNA kit was obtained from Tiangen Biotech Co., Ltd. (Beijing, China). A RevertAid First Strand cDNA Synthesis kit was obtained from Thermo Fisher Scientific, Inc. (Waltham, MA, USA). SYBR ${ }^{\circledR}$ Premix Ex Taq ${ }^{\mathrm{TM}}$ II (Tli RNaseH Plus) was purchased fromTakara Bio, Inc. (Otsu, Japan). The total superoxide dismutase (T-SOD) assay kit (cat. no. A001-1-1), glutathione peroxidase (GSH-PX) assay kit (cat. no. A005), catalase (CAT) assay kit (cat. no. A007-1-1) and malondialdehyde (MDA) assay kit (cat. no. A003-1) were purchased from Nanjing Jiancheng Bioengineering Institute (Nanjing, China).

High-performance liquid chromatography to determine rhein content. The content of rhein was determined using an L-2000 Liquid Chromatography system (Hitachi, Ltd., Tokyo, Japan) equipped with an L-2200 auto-injection device. Chromatographic analysis was preformed with a reverse-phase YMC-Pack Pro $\mathrm{C}_{18}$ column $(5 \mu \mathrm{m} ; 4.6 \times 250 \mathrm{~mm})$. The isocratic mobile phase comprised $0.5 \%$ aqueous acetic acid solution and methanol $(40: 60, v / v)$ at a flow rate of $1.0 \mathrm{ml} / \mathrm{min}$ and detection was performed at $435 \mathrm{~nm}$ using an L-2455 UV-VIS detector (Hitachi, Ltd.). Total analysis time was $15 \mathrm{~min}$ and analysis was performed at a temperature of $40^{\circ} \mathrm{C}$. The injection volume of rhein was $10 \mu \mathrm{l}$. The results revealed that the exact purity of rhein was 98\%, which was consistent with the result provided by the manufacturer.

Animals. A total of 144 male specific pathogen free Sprague-Dawley rats (weighing 260-300 g, aged 8-10 weeks old) were obtained from the Laboratory Animal Center of Ningxia Medical University (Yinchuan, China). All animal handling procedures were approved by the Animal Research Ethics Committee, School of Ningxia Medical University (Yinchuan, China). Animals were maintained in a $12 \mathrm{~h} \mathrm{light} /$ dark cycle at room temperature $\left(23 \pm 2^{\circ} \mathrm{C}\right)$ in $60 \%$ humidity. The animals had ad libitum access to food and water. Rats were randomly divided into 6 groups (each, $n=24$ ) as follows: Sham, I/R, I/R $+12 \mathrm{mg} / \mathrm{kg}$ /day nimodipine $(25,26)$, and $\mathrm{I} / \mathrm{R}+25,50$ or $100 \mathrm{mg} / \mathrm{kg} /$ day rhein (27). Nimodipine was used as a control, as it acts as a neuroprotectant. The sham and I/R groups received $0.5 \%$ sodium carboxymethyl cellulose orally for 3 days following cerebral ischemic/reperfusion induced by MCAO, and the other groups received nimodipine $(12 \mathrm{mg} / \mathrm{kg} /$ day $)$ and rhein $(25,50$ or $100 \mathrm{mg} / \mathrm{kg} /$ day $)$ orally for 3 days following cerebral ischemic/reperfusion induced by MCAO.

MCAO model. As previously stated, MCAO induces ischemic injury (28). Rats were anesthetized with $7 \%$ chloral hydrate $(350 \mathrm{mg} / \mathrm{kg})$ via intraperitoneal injection. The right common carotid artery (CCA), the external carotid artery and the internal carotid artery (ICA) were exposed. A nylon wire $(1.8 \pm 0.5 \mathrm{~cm})$ was advanced from the CCA into the ICA until it blocked the original MCA. Reperfusion was performed by withdrawing the nylon wire following $2 \mathrm{~h}$ ischemia. The sham-operated rats were treated by the same surgical procedure however the nylon wire was not introduced.

Determination of the NFS.NFSs were obtained from randomly selected mice from each group $(\mathrm{n}=8) 72 \mathrm{~h}$ post reperfusion and they were evaluated according to the Zea Longa's score criteria. The deficit criteria used have been previously described (29). The scoring details were as follows: 0, No noticeable neurological deficit; 1 , failed to extend opposite forepaw; 2 , circled to the contralateral side; 3 , tumbled to its side while walking due to hemiplegia; 4 , loss of consciousness or mortality. 
Determination of the area of cerebral infarction. Rats were anesthetized by intraperitoneal injection of $7 \%$ chloral hydrate $(350 \mathrm{mg} / \mathrm{kg})$. Rats were decapitated and then the whole brain was removed. Subsequently, coronary brain slices (2-mm sections) were stained using 2\% TTC chloride for $30 \mathrm{~min}$ at $37^{\circ} \mathrm{C}$ and then fixed in $10 \%$ formalin solution at $25^{\circ} \mathrm{C}$ for $1 \mathrm{~h}$ $(n=6)$. The infarcted area was stained white, whereas normal brain tissue was red. Stained cerebral slices were photographed using a Nikon D7100 camera (Nikon Corporation, Tokyo, Japan). Cerebral infarct areas were determined using microscope image-analysis software (Image Pro plus, version 6.0; Media Cybernetics, Rockville, MD, USA). The ratio of the infarcted area to the total brain area was calculated using the following equation: Percentage of infarct volume=infarct volume/(infarct volume + normal volume) x100.

Hematoxylin and eosin staining. Prior to this procedure, rats were anesthetized by intraperitoneal injection of $7 \%$ chloral hydrate $(350 \mathrm{mg} / \mathrm{kg})$ and perfused transcardially with $100 \mathrm{ml}$ of $0.9 \%$ sodium chloride, followed by $200 \mathrm{ml} 4 \%$ paraformaldehyde. Rats were decapitated and then the whole brain was removed. Rat brains were fixed in $4 \%$ formaldehyde at $25^{\circ} \mathrm{C}$ for $2 \mathrm{~h}$. Brains were soaked in distilled water for $4 \mathrm{~h}$, dehydrated in increasing concentrations of alcohol, hyalinized by dimethylbenzene, embedded in paraffin and sectioned to a thickness of $4-\mu \mathrm{m}$. Sections were adhered to glass slides prepared with poly-L-Lysine and stored at $4^{\circ} \mathrm{C}$. Following continual dewaxing and routine washing, paraffin-embedded sections were stained with hematoxylin for $5 \mathrm{~min}$, followed by color separation using $1 \%$ hydrochloric acid alcohol for $20 \mathrm{sec}$. Sections were then incubated with $1 \%$ ammonia for $30 \mathrm{sec}$, stained with eosin for $5 \mathrm{~min}$ and subsequently dehydrated using alcohol, hyalinized using dimethylbenzene and sealed with neutral gum. All the aforementioned steps were performed at $25^{\circ} \mathrm{C}$. A total of five non-overlapping views of the cortex in each section were randomly selected and observed under a light microscope for cell counting at a magnification of $\mathrm{x} 400$. The degenerated cell index (number of degenerated cells/total cells) indicated the degree of damage.

Determination of oxidative stress indicators. Levels of SOD, GSH-Px, CAT and MDA in the ischemic brain were measured $72 \mathrm{~h}$ following I/R. The right cortical samples ( $\mathrm{n}=6$ per group) were weighed. The SOD, GSH-Px and CAT activities and MDA level were obtained using the T-SOD, GSH-Px, CAT and MDA assay kits according to the manufacturer's protocol (Nanjing Jiancheng Bioengineering Institute, Co., Ltd., Nanjing, China). SOD, GSH-Px and CAT activities were expressed as units/mg protein. The amount of lipid peroxide was obtained as the product of MDA. MDA concentrations were expressed as nmol/mg protein.

Western blot analysis. Frozen right brains were homogenized in cold whole cell lysis buffer (cat. no. KGP2100; Nanjing KeyGen Biotech Co., Ltd., Nanjing, China), sonicated twice on ice for $5 \mathrm{sec}$ each time and centrifuged at 12,000 x $\mathrm{g}$ for $5 \mathrm{~min}$ at $4^{\circ} \mathrm{C}$ to remove cell debris. Total protein concentration in the supernatant was determined using the BCA protein assay kit. A total of $80 \mu \mathrm{g}$ protein per lane was separated using $10 \%$ SDS-PAGE and transferred to polyvinylidene difluoride membranes. Membranes were blocked with 5\% non-fat dried milk for $1 \mathrm{~h}$ at $25^{\circ} \mathrm{C}$ and subsequently incubated with primary antibodies against Bcl-2 (1:500), Bax (1:500), caspase-9 $(1: 1,000)$, caspase-3 $(1: 1,000)$, cleaved caspase-3 $(1: 1,000), \beta$-actin $(1: 1,000)$ and GAPDH $(1: 2,000)$ overnight at $4^{\circ} \mathrm{C}$. Membranes were washed with PBST and subsequently incubated with horseradish peroxidase-conjugated goat anti-rabbit immunoglobulin G secondary antibodies $(1: 1,000)$ for $2 \mathrm{~h}$ at room temperature. Following washing, membranes were developed using a Chemidoc ${ }^{\mathrm{TM}}$ XRS Imaging system (Bio-Rad Laboratories, Inc., Hercules, CA, USA). The signal intensities of the bands of interest were quantified and normalized to $\beta$-actin or GAPDH using the Image-Pro Plus software version 6.0 (Media Cybernetics, Inc.).

Reverse transcription-quantitative-polymerase chain reaction analysis (RT-qPCR). RT-qPCR was used to assess the mRNA expression levels of caspase-9 and caspase-3 $72 \mathrm{~h}$ following reperfusion. Total RNA was extracted using a total RNA kit according to the manufacturer's protocol. Labeled cDNA was prepared using the RevertAid First Strand cDNA Synthesis kit from the total RNA samples. For PCR amplification, a CFX96 Real-Time system was used. cDNA was added to each reaction to a final reaction volume of $25 \mu$ l containing $1 X$ SYBR Premix Ex Taq II. The thermocycling conditions used were as follows: Initial denaturation at $95^{\circ} \mathrm{C}$ for $30 \mathrm{sec}$., followed by 40 cycles comprising of denaturation at $95^{\circ} \mathrm{C}$ for $5 \mathrm{sec}$, annealing at $60^{\circ} \mathrm{C}$ for $30 \mathrm{sec}$, elongation at $72^{\circ} \mathrm{C}$ for $30 \mathrm{sec}$ and a final extension step at $72^{\circ} \mathrm{C}$ for $5 \mathrm{~min}$. $\beta$-actin was used as the reference gene for the normalization of different transcript values and normalized mRNA levels were expressed as $2^{-\Delta \Delta \mathrm{Cq}}$ $\left(\Delta \Delta \mathrm{Cq}=\mathrm{Cq}_{\text {target }}-\mathrm{Cq}_{\beta \text {-actin }}\right.$ ) (30). Only one produced PCR product was subjected to melting curve analysis. Sequences of the primers used are listed in Table I.

Statistical analysis. Statistical analysis was conducted using SPSS 17.0 (SPSS, Inc., Chicago, IL, USA). The results were presented as the mean \pm standard deviation. Differences among $>2$ groups were assessed using one-way analysis of variance followed by the least significant difference post hoc test. Differences between two groups were analyzed using an unpaired t-test. $\mathrm{P}<0.05$ was considered to indicate a statistically significant difference.

\section{Results}

Rhein ameliorates NFSs. NFSs were obtained using the Zea Longa's criteria $72 \mathrm{~h}$ following cerebral reperfusion. Severe dysfunction on each test was indicated by a high NFS score of 2-3. The NFSs of the I/R group were significantly higher than those of the sham group $(\mathrm{P}<0.01$; Table II). However, the NFSs were significantly decreased in the groups treated with 50 and $100 \mathrm{mg} / \mathrm{kg}$ rhein $(\mathrm{P}<0.05$ and $\mathrm{P}<0.01$, respectively) and nimodipine $(\mathrm{P}<0.05)$ compared with the $\mathrm{I} / \mathrm{R}$ group, thereby indicating that rhein treatment improves neurological function impaired by cerebral I/R.

Rhein reduces the area of cerebral infarction. Infarcted cerebral volume was measured $72 \mathrm{~h}$ following cerebral reperfusion by TTC staining. The infarcted area (white) was primarily 

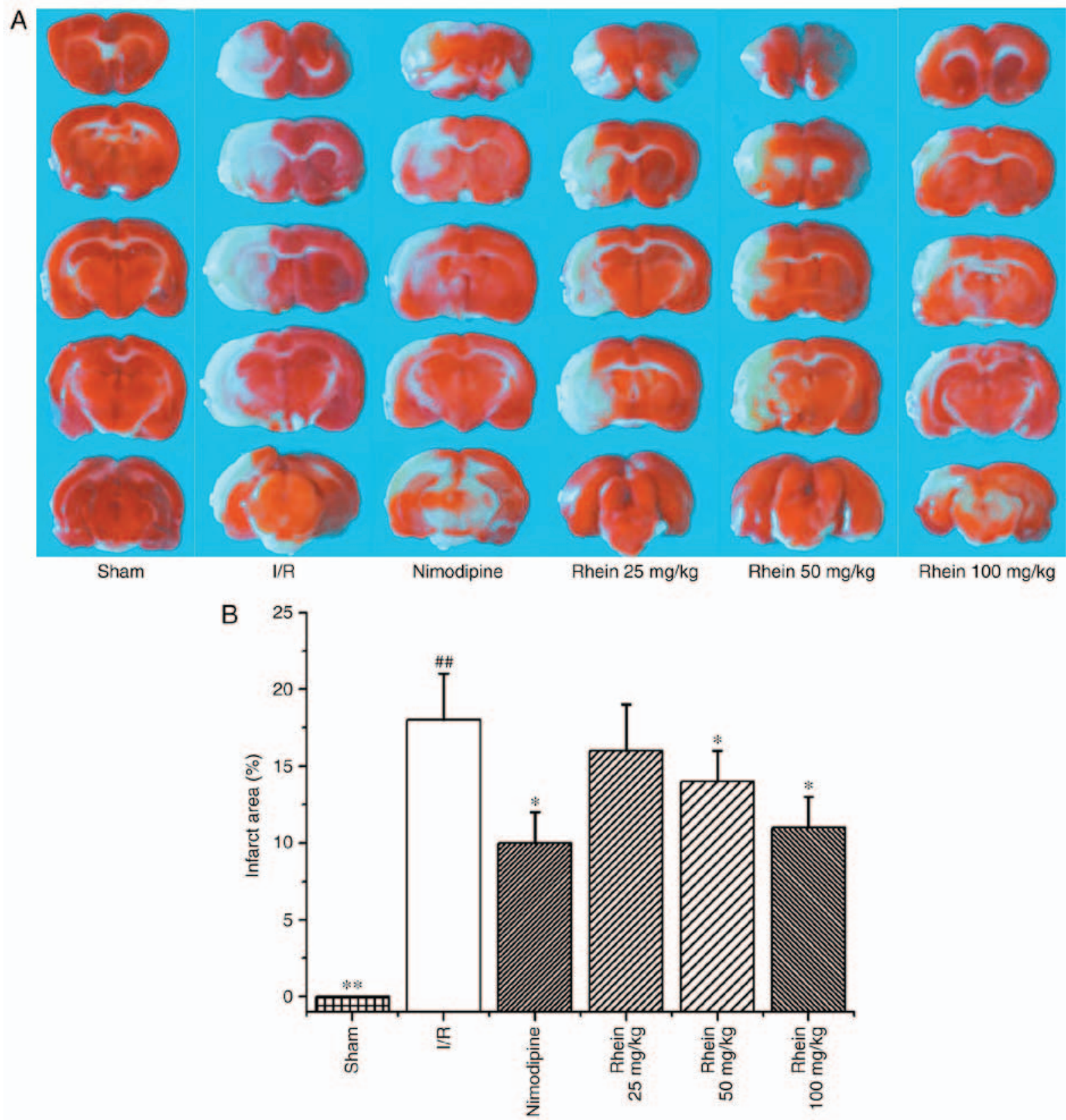

Figure 1. Effect of rhein on the area of cerebral infarction in I/R rats. (A) TTC staining. (B) Quantification of TTC staining results. Values are presented as the mean \pm standard deviation. $\mathrm{n}=6$ /group. ${ }^{\# \prime} \mathrm{P}<0.01$ vs. the sham group; ${ }^{*} \mathrm{P}<0.05$ and ${ }^{* *} \mathrm{P}<0.01$ vs. the $\mathrm{I} / \mathrm{R}$ group. I/R, ischemic/reperfusion; TTC, 2,3,5-triphenyltetrazolium chloride.

located at the striatum and parts of the cortex frontoparietal lobe in the right hemisphere (Fig. 1A). The infarcted cerebral area of the I/R group was significantly greater than that of the sham group $(\mathrm{P}<0.01)$. By contrast, theinfarcted cerebral area of the nimodipine and 50 and $100 \mathrm{mg} / \mathrm{kg}$ rheingroups were significantly smaller than the I/R group (each $\mathrm{P}<0.05$; Fig. 1B), thereby indicating that treatment with rhein reduces cerebral injury induced by cerebral I/R.

Histological changes. Hematoxylin and eosin staining (Fig. 2) revealed that nerve cell arrangement was well organized, exhibiting a complete structure in the control group (Fig. 2A). However, $72 \mathrm{~h}$ following ischemia, in the $\mathrm{I} / \mathrm{R}$ group the neuron arrangement became irregular with deeply colored and condensed nuclei, increased gaps around the nerves and degenerative changes, including the formation of vacuoles and necrosis in a number of the neurons (Fig. 2B). In addition, the denatured cell index (DCI) values in the I/R group were significantly higher than those of the sham group $(\mathrm{P}<0.01$; Fig. $2 \mathrm{G})$. In the nimodipine and rhein groups, nerve cell damage was milder compared with that of the model group and neurons were well arranged, with clear outlines, nuclear condensation, and shriveled bodies. DCI values in all the rhein groups and the nimodipine group were significantly decreased compared with the I/R group $(\mathrm{P}<0.05$ or $\mathrm{P}<0.01$; Fig. $2 \mathrm{G})$. Deep coloration was observed in only a few cells and there were no significant differences in DCI values between the different rhein groups.

Effect of rhein on oxidative stress indicators induced by I/R. The activities of the SOD, GSH-Px and CAT enzymes were 

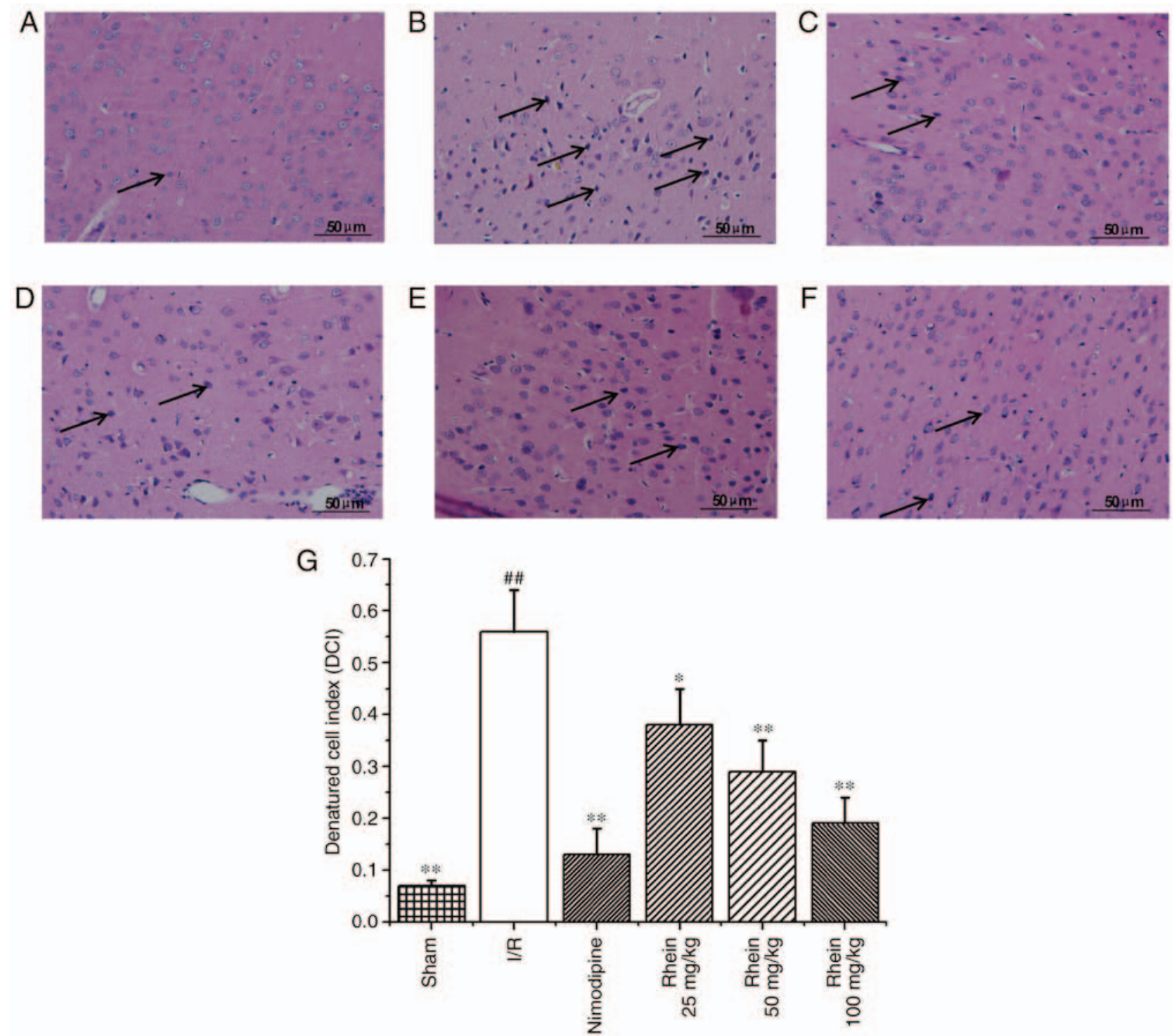

Figure 2. Effect of rhein on nerve cell morphology and structure in the cortices of $I / R$ rats. Hematoxylin and eosin staining in the (A) sham, (B) I/R, (C) nimodipine, (D) 25, (E) 50 and (F) $100 \mathrm{mg} / \mathrm{kg}$ rhein treatment groups. Arrows indicate denatured cells. Magnification, $\mathrm{x} 400$. (G) The denatured cell index for all groups. ${ }^{\# \#} \mathrm{P}<0.01$ vs. the sham group; ${ }^{*} \mathrm{P}<0.05$ and ${ }^{* *} \mathrm{P}<0.01$ vs. the $\mathrm{I} / \mathrm{R}$ group. I/R, ischemic/reperfusion.

significantly reduced in the I/R group compared with those in the sham group $(\mathrm{P}<0.01 ;$ Fig. 3A-C). However, treatment with nimodipine and 50 and $100 \mathrm{mg} / \mathrm{kg}$ rhein, significantly increased the activities of SOD, GSH-Px and CAT compared with the $\mathrm{I} / \mathrm{R}$ group $(\mathrm{P}<0.01$ or $\mathrm{P}<0.05)$. Treatment with $25 \mathrm{mg} / \mathrm{kg}$ rhein also significantly increased the activity of SOD compared with the $\mathrm{I} / \mathrm{R}$ group $(\mathrm{P}<0.05)$. MDA was used as a biomarker for lipid peroxidation and oxidative stress. MDA content was significantly higher in the ischemic cortices of the I/R group compared with the sham group $(\mathrm{P}<0.01$; Fig. 3D). However, following treatment with nimodipine and all doses of rhein, MDA content was significantly decreased compared with the $\mathrm{I} / \mathrm{R}$ group $(\mathrm{P}<0.01$ or $\mathrm{P}<0.05)$.

Rhein inhibits BAX expression and enhances Bcl-2 expression. Western blot analysis revealed that the expression of Bcl-2 was significantly reduced $(\mathrm{P}<0.05$; Fig. $4 \mathrm{~A}$ and $\mathrm{C})$ and that BAX protein expression was significantly enhanced in the I/R group compared with the sham group $(\mathrm{P}<0.05$;
Fig. 4A and D). Compared with the I/R group, treatment with nimodipine and $100 \mathrm{mg} / \mathrm{kg}$ rhein significantly upregulated Bcl-2 expression $(\mathrm{P}<0.05$; Fig. $4 \mathrm{~A}$ and $\mathrm{C})$. Furthermore, treatment with nimodipine and 50 and $100 \mathrm{mg} / \mathrm{kg}$ rhein significantly downregulated BAX expression $(\mathrm{P}<0.05$; Fig. 4A and D). The Bcl-2/BAX ratio was also significantly increased following treatment with nimodipine and 50 or $100 \mathrm{mg} / \mathrm{kg}$ rhein compared with the I/R group $(\mathrm{P}<0.05$ or $\mathrm{P}<0.01$; Fig. 4B).

Rhein inhibits the expression of caspase-9, caspase- 3 and cleaved caspase-3. Western blot analysis revealed that the expression of caspase- 9 in the I/R group was significantly higher than in the sham group $(\mathrm{P}<0.05 ;$ Fig. 5). Treatment with 50 and $100 \mathrm{mg} / \mathrm{kg}$ rhein significantly reduced the expression of caspase-9 compared with the $I / R$ group $(\mathrm{P}<0.05)$. In the I/R group, levels of caspase-3 $(\mathrm{P}<0.01)$ and cleaved caspase- 3 $(\mathrm{P}<0.05)$ expression were significantly higher than in the sham group (Fig. 6). The administration of nimodipine and 

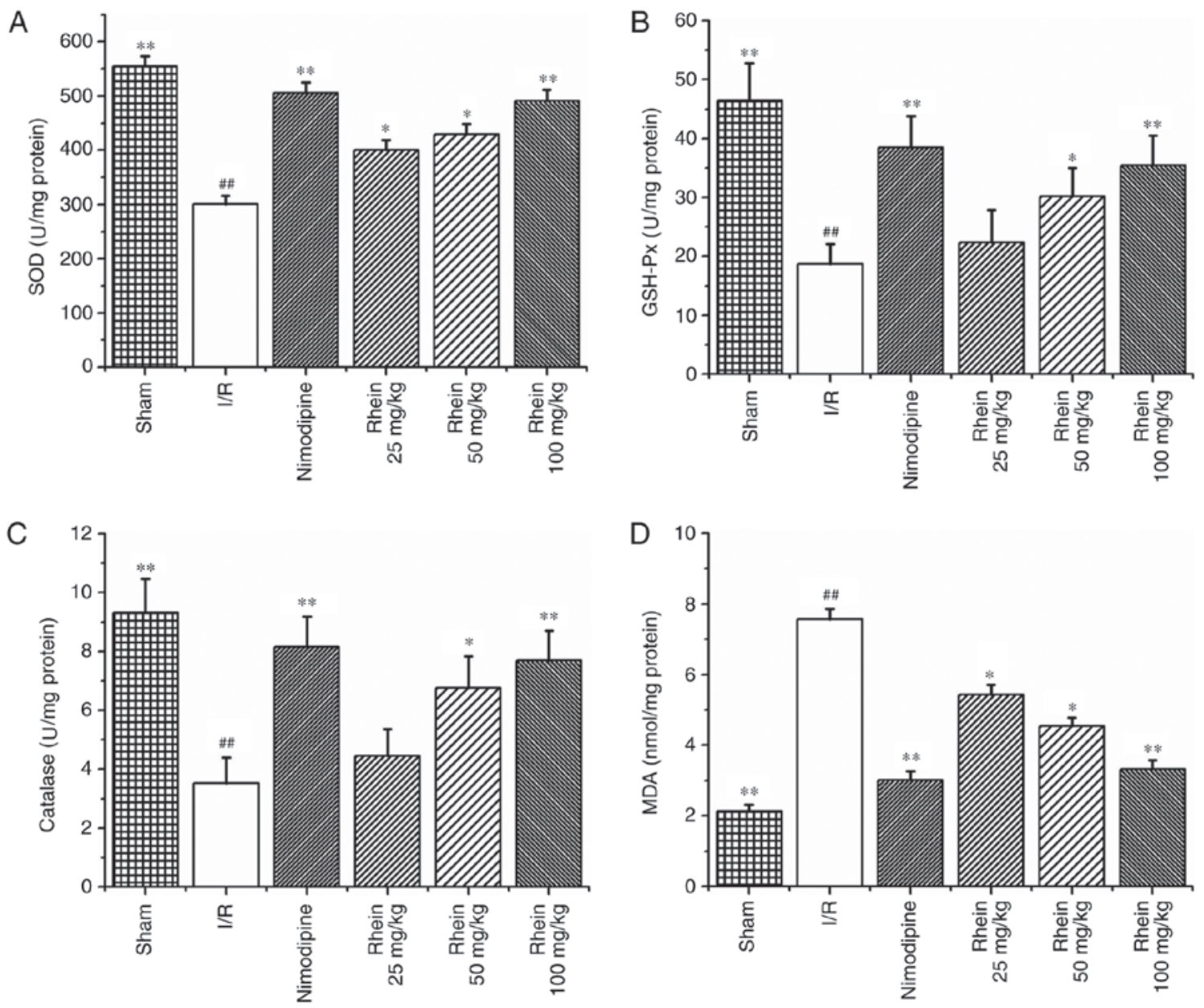

Figure 3. Rhein attenuates oxidative stress following I/R in rats. Effect of rhein administration on (A) SOD, (B) GSH-Px, (C) catalase and (D) MDA expression. Values are presented as the mean \pm standard deviation $(n=6)$. ${ }^{\# \#} \mathrm{P}<0.01$ vs. the sham group; ${ }^{*} \mathrm{P}<0.05$ and ${ }^{* *} \mathrm{P}<0.01$ vs. the $\mathrm{I} / \mathrm{R}$ group. SOD, superoxide dismutase; GSH-Px, glutathione-peroxidase; MDA, malondialdehyde; I/R, ischemic/reperfusion.

Table I. The primers for reverse transcription-quantitative polymerase chain reaction.

\section{Gene}

Caspase-3

Caspase-9

$\beta$-actin

$$
\text { Sequence (5'-3') }
$$

F: AAAGGATGACTGGGAGTGG
R: ATGACGACCTGGAACATCG
F: TATGGCACAGATGGATGCTC
R: CTTTCTGCTCACCACCACAG
F: CCCATCTATGAGGGTTACGC
R: TTTAATGTCACGCACGATTTC

F, forward; R, reverse.

50 and $100 \mathrm{mg} / \mathrm{kg}$ rhein significantly reduced the expression of caspase-3 $(\mathrm{P}<0.05)$, whereas administration of nimodipine and all doses of rhein significantly reduced the expression of cleaved caspase-3 $(\mathrm{P}<0.05)$.

RT-qPCR results revealed that levels of caspases-9 and -3 mRNA expression were significantly increased in the I/R group compared with the sham group $(\mathrm{P}<0.05$; Fig. 7). However, treatment with 50 and $100 \mathrm{mg} / \mathrm{kg}$ rhein significantly decreased levels of caspases-9 and -3 mRNA $(\mathrm{P}<0.05)$.
Table II. The protective effects of rhein on neurological functional score in rats $72 \mathrm{~h}$ post reperfusion.

\begin{tabular}{lc}
\hline Group & Neurological functional score \\
\hline Sham & $0.0 \pm 0.0$ \\
I/R & $2.2 \pm 0.8^{\mathrm{a}}$ \\
Nimodipine & $1.0 \pm 0.7^{\mathrm{b}}$ \\
Rhein $(25 \mathrm{mg} / \mathrm{kg})$ & $2.0 \pm 0.9$ \\
Rhein $(50 \mathrm{mg} / \mathrm{kg})$ & $1.6 \pm 0.5^{\mathrm{b}}$ \\
Rhein $(100 \mathrm{mg} / \mathrm{kg})$ & $1.1 \pm 0.9^{\mathrm{c}}$ \\
\hline
\end{tabular}

Data are presented as the mean \pm standard deviation. $n=8$ /group. ${ }^{\mathrm{a}} \mathrm{P}<0.01$ vs. the sham group; ${ }^{\mathrm{b}} \mathrm{P}<0.05$ and ${ }^{\mathrm{c}} \mathrm{P}<0.01$ vs. the $\mathrm{I} / \mathrm{R}$ group. $\mathrm{I} / \mathrm{R}$, ischemic/reperfusion.

\section{Discussion}

In the present study, the infarcted cerebral area was identified by TTC staining and NFS was evaluated $72 \mathrm{~h}$ following reperfusion. Treatment with rhein markedly decreased the infarcted cerebral area and significantly improved the NFS. These results indicate that rhein may protect against cerebral I/R injury. 

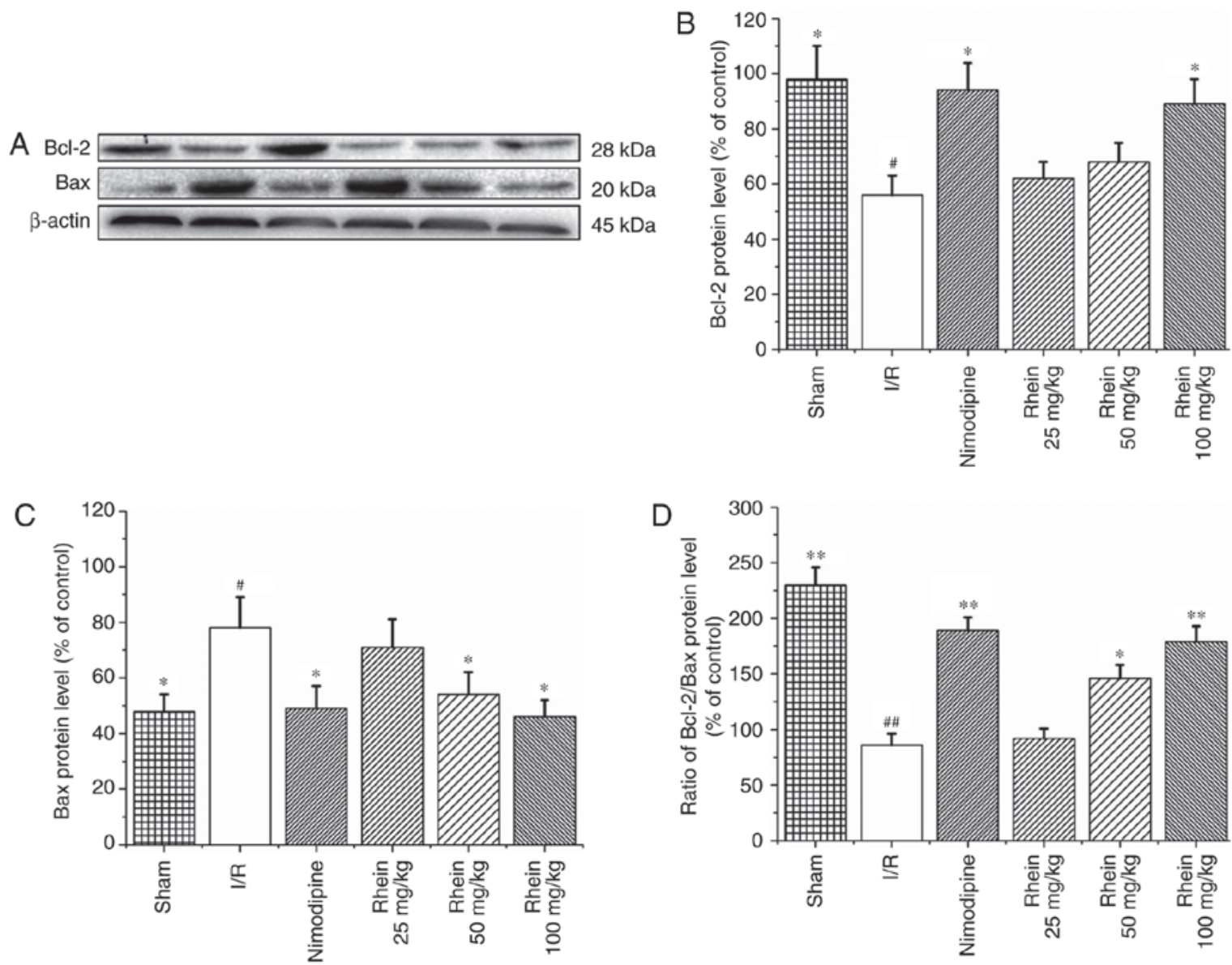

Figure 4. Effect of rhein on the expression of Bcl-2 and BAX. (A) Representative western blots of Bcl-2 and BAX expression. $\beta$-actin was used as the loading control. Quantification of (B) Bcl-2 and (C) BAX expression. (D) The Bcl-2/BAX ratio. Values are presented as the mean \pm standard deviation ( $\mathrm{n}=6$ ). ${ }^{\#} \mathrm{P}<0.05$ and ${ }^{\# \#} \mathrm{P}<0.01$ vs. the sham group; ${ }^{*} \mathrm{P}<0.05$ and ${ }^{* *} \mathrm{P}<0.01$ vs. the $\mathrm{I} / \mathrm{R}$ group. $\mathrm{I} / \mathrm{R}$, ischemic/reperfusion; Bcl-2, B-cell lymphoma-2; BAX, apoptosis regulator Bax.

Ischemic stroke is the cumulative effect of numerous mechanisms including oxidative stress, excitotoxicity, intracellular calcium overload, inflammation and apoptosis (31). Oxidative stress secondary to ROS formation and neuron apoptosis is crucial in stimulating the progression of ischemic stroke (32). Under normal physiological conditions, low levels of ROS exist within the brain (6). Excessive ROS are removed by endogenous antioxidant enzymes including SODs (33), GSH-Px and CATs (34). SOD converts superoxide anions into hydrogen peroxide and GSH-Px uses GSH to reduce $\mathrm{H}_{2} \mathrm{O}_{2}$ to water (35). MDA, which is a poisonous end product of lipid peroxidation, is able to directly reflect the rate and extent of lipid peroxidation and indirectly reflects the capacity of free radical elimination (36). Previous studies have demonstrated that increasing the SOD, CAT and GSH-Px levels and decreasing MDA concentrations significantly protects against oxidative stress during ischemic stroke (7,9-11). The results of the present study were consistent with the aforementioned previous studies. The protective effects of rhein in I/R injury may be associated with its enhancing effect on endogenous antioxidant capability, which mitigates oxidative stress during cerebral I/R. Therefore, the enhancement of the antioxidant system represents a potential target for novel therapies to treat patients with ischemic stroke.

Ischemic stroke results in ROS overproduction in the mitochondria (37) and specific ROS, including $\mathrm{H}_{2} \mathrm{O}_{2}$ or superoxide, are crucial mediators of apoptosis $(38,39)$. Apoptosis is induced
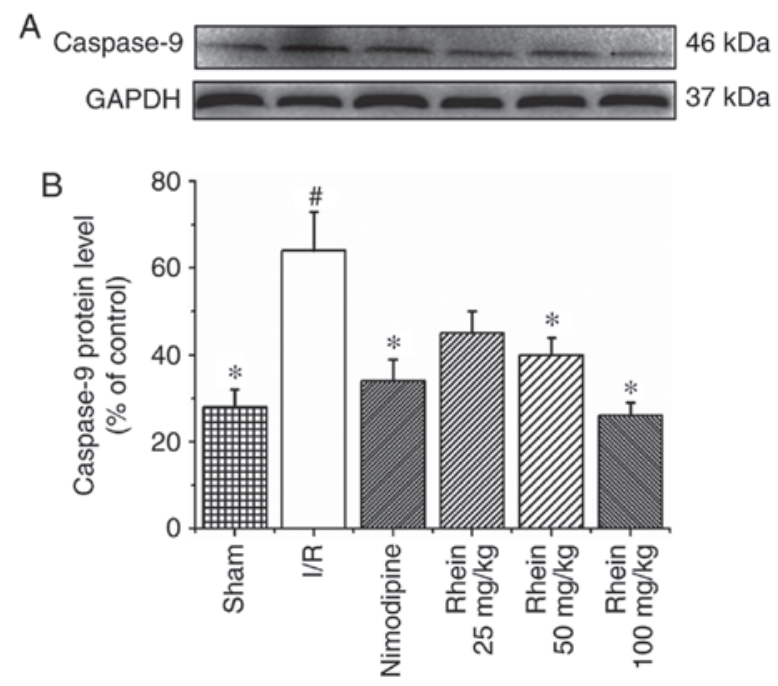

Figure 5. Effect of rhein on caspase-9 expression. (A) Representative western blots of caspase-9 expression. GAPDH was used as the loading control. (B) Quantification of caspase-9 expression. Values are presented as the mean \pm standard deviation $(n=6)$. ${ }^{\#} \mathrm{P}<0.05$ vs. the sham group; ${ }^{*} \mathrm{P}<0.05$ vs. the $\mathrm{I} / \mathrm{R}$ group. I/R, ischemic/reperfusion.

via extrinsic and intrinsic pathways (40). In the intrinsic pathway, the loss of transmembrane potential leads to mitochondrial respiration failure and enhanced ROS generation, 

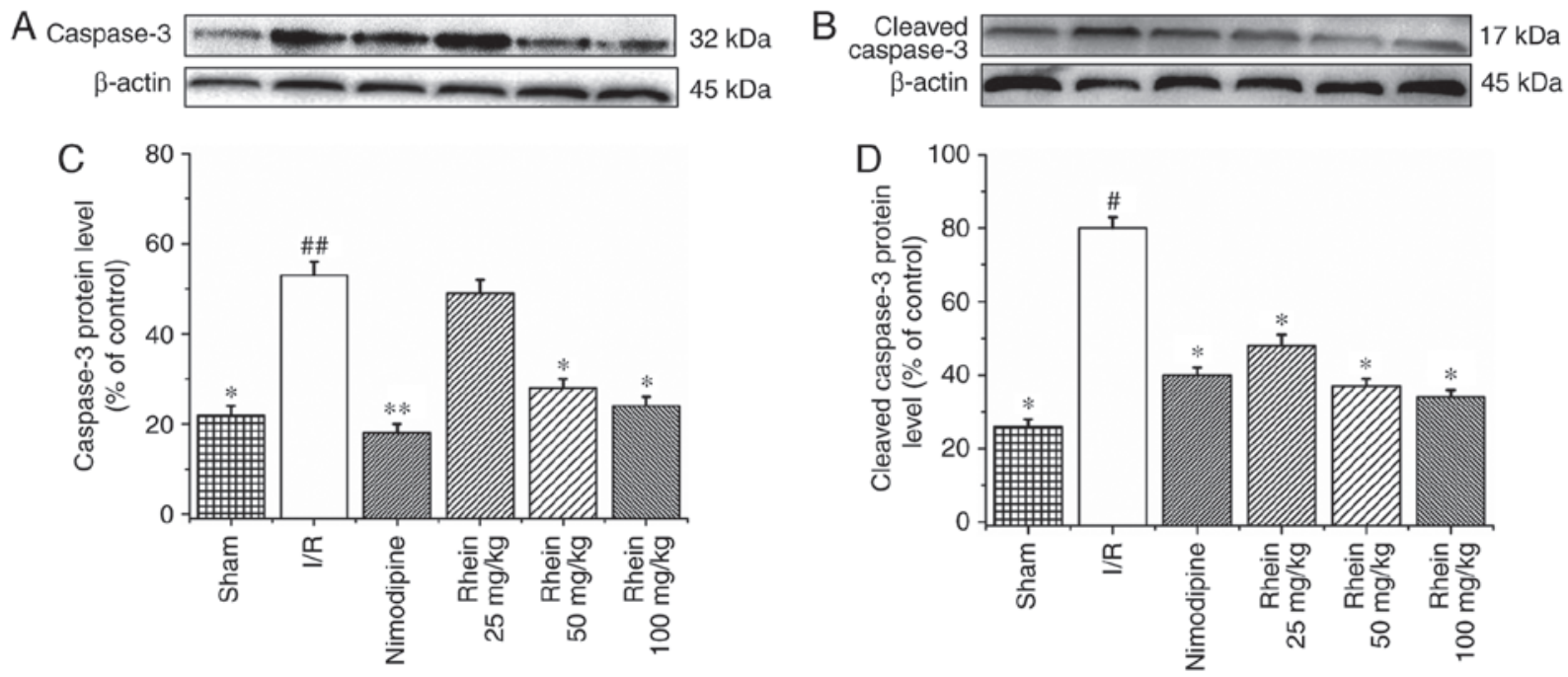

Figure 6. Effect of rhein on the protein expression levels of caspase-3 and cleaved caspase-3. Western blot analysis of (A) caspase-3 and (B) cleaved caspase-3 expression. $\beta$-actin was used as the loading control. Quantitative data of (C) caspase-3 and (D) cleaved caspase-3 are given as percentages of the value in control rats. Values are presented as the mean \pm standard deviation $(\mathrm{n}=6)$. ${ }^{\#} \mathrm{P}<0.05$ and ${ }^{\# \#} \mathrm{P}<0.01$ vs. the sham group; ${ }^{*} \mathrm{P}<0.05$ and ${ }^{* * *} \mathrm{P}<0.01$ vs. the $\mathrm{I} / \mathrm{R}$ group. $\mathrm{I} / \mathrm{R}$, ischemic/reperfusion.
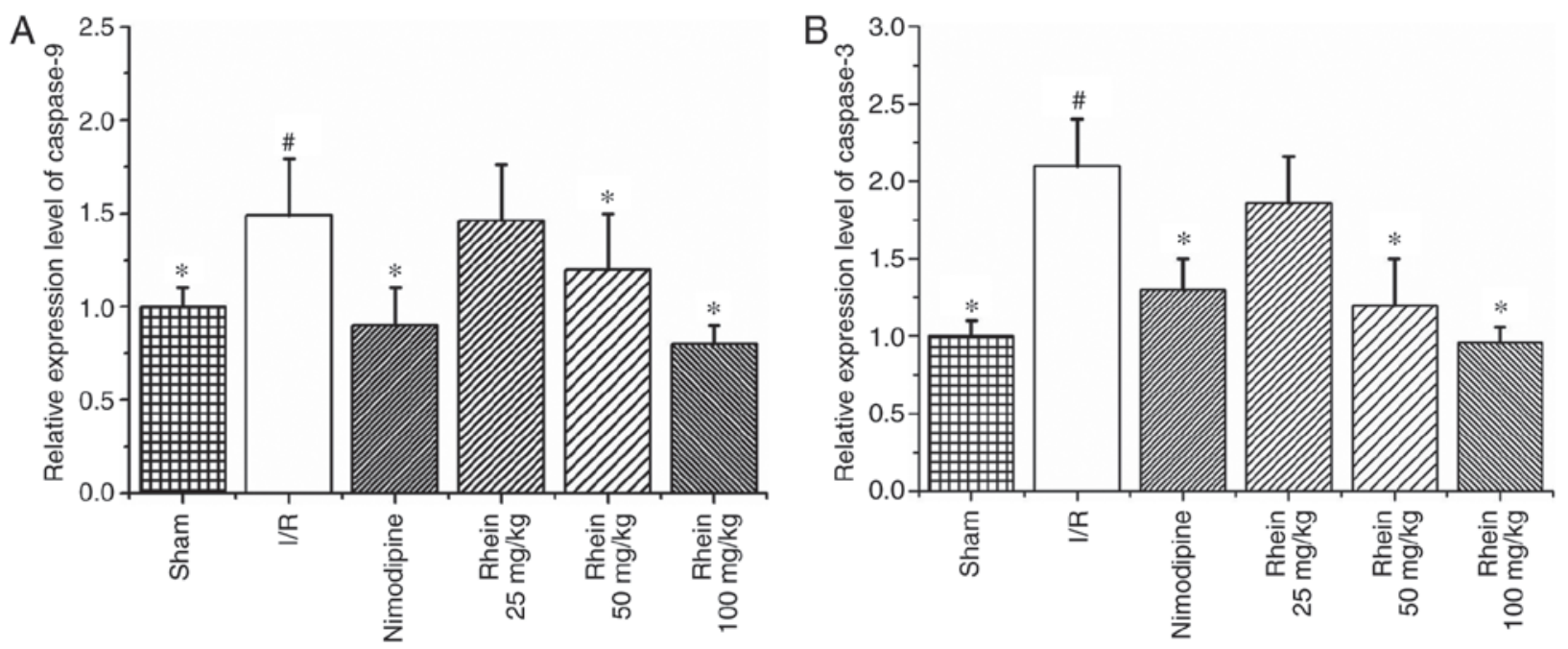

Figure 7. Effect of rhein on the mRNA expression of caspases-9 and -3. (A) Expression of caspase-9 mRNA. (B) The expression of caspase-3 mRNA. Values are presented as the mean \pm standard deviation $(n=6)$. ${ }^{"} \mathrm{P}<0.05$ vs. the sham group; ${ }^{*} \mathrm{P}<0.05$ vs. the $\mathrm{I} / \mathrm{R}$ group. $\mathrm{I} / \mathrm{R}$, ischemic/reperfusion.

which accelerates cytochrome $c$ release from the mitochondria (41). The release of cytochrome $c$ via this mechanism may be associated with the Bcl-2 family of proteins $(40,42)$. When cytochrome $c$ forms a complex with apoptotic protease-activating factor 1 apoptosomes are formed, which activate caspase-9 and consequently activate caspase-3 (43), DNA-breaking enzymes, including endonucleases (44), and repair enzymes, including poly ADP-ribose polymerase (45), leading to cell death. The extrinsic apoptosis pathway activates caspase-8, which either activates executioner caspases, such as caspase-3, or the intrinsic apoptotic pathway $(46,47)$.

Apoptosis is caused by an imbalance between pro-apoptotic and anti-apoptotic signals. Bcl-2 is an anti-apoptotic protein that intercepts the release of cytochrome $c$ in response to various apoptotic signals, thereby inhibiting apoptosis. BAX is a pro-apoptotic protein that accelerates cytochrome $c$ release from the mitochondria, thereby leading to cell death (48-51). It has been demonstrated that the $\mathrm{Bcl}-2 / \mathrm{BAX}$ ratio is decreased in the cerebrum of rats following $\mathrm{I} / \mathrm{R}(52,53)$. The results of the present study illustrated that the expression of $\mathrm{Bcl}-2$ was significantly inhibited whereas the expression of BAX was significantly increased following $\mathrm{I} / \mathrm{R}$, which is consistent with the results of previous studies. The Bcl-2/BAX ratio was significantly reduced in the cerebrum of rats following I/R; however the administration of $100 \mathrm{mg} / \mathrm{kg}$ rhein significantly reversed the decrease in Bcl-2 expression. In addition, 50 and $100 \mathrm{mg} / \mathrm{kg}$ rhein significantly inhibited the increase in BAX expression. The ratio of $\mathrm{Bcl}-2 / \mathrm{BAX}$ was significantly increased following the administration of 50 and $100 \mathrm{mg} / \mathrm{kg}$ rhein. The administration of $100 \mathrm{mg} / \mathrm{kg}$ rhein was more effective than $50 \mathrm{mg} / \mathrm{kg}$ rhein. The results indicate that rhein may prevent cerebral I/R injury by upregulating Bcl-2 and downregulating $\mathrm{BAX}$ expression, thereby increasing the $\mathrm{Bcl}-2 / \mathrm{BAX}$ ratio and inhibiting apoptosis. 
Caspases are central regulators of apoptosis and serve keys roles in ischemia-induced cytotoxicity (54). Caspases may be classified into two groups, initiators (caspase-9) and effectors (caspase-3), based on their function (55). Typically, initiator caspases activate downstream effector caspases through a proteolytic cascade, resulting in the cleavage of cellular substrates involved in apoptosis (56). Caspase-3 may be activated by caspase- 9 via the mitochondria-dependent cytochrome $c /$ caspase-9 intrinsic pathway (57). In addition, increased BAX expression may induce the activation of caspase- 9 within the mitochondria (58). Caspases- -9 and -3 are upregulated and activated in ischemic brain tissues (59) and pharmacological or genetic inhibition of caspase-3 reduces neuronal death in the ischemic brain (60). The present study demonstrated that oral rhein administration maintains low caspase-9 levels. Rhein at doses of 50 and $100 \mathrm{mg} / \mathrm{kg}$ significantly inhibited caspase- 9 expression. Caspase-3 expression in the I/R group was significantly higher than in the sham group; however, administration with $100 \mathrm{mg} / \mathrm{kg}$ rhein significantly inhibited its expression. Cleaved caspase- 3 is a key executioner of apoptosis. The results of the present study revealed that cleaved caspase- 3 expression in the I/R group was significantly higher than that of the sham group, which was consistent with the results obtained by Wang et al (61). However, administration of 50 and $100 \mathrm{mg} / \mathrm{kg}$ rhein significantly inhibited the expression of cleaved caspase-3.

In conclusion, the present study demonstrated that treatment with rhein markedly reduces the area of brain infarction and reduces neuronal apoptosis in a rat model of I/R injury. The protective effects of rhein were mediated through the augmentation of endogenous antioxidant defenses and the inhibition of the oxidative stress pathway in the ischemic rat brain. In addition, rhein exhibited anti-apoptotic effects. These results suggest that rhein may be beneficial in the treatment of ischemic stroke. However, further studies are required to confirm these results prior to its use in humans.

\section{Acknowledgements}

Not applicable.

\section{Funding}

The present study was supported by the National Natural Science Foundation of China (grant nos. 81660700 and 81260679), Ningxia College first-class discipline construction project (Chinese medicine) funded project (grant no. NXYLXK2017A06), the college students innovation training program of Ningxia Hui Autonomous Region (grant nos. NXCX2015183 and NXCX2016162).

\section{Availability of data and materials}

The analyzed data sets generated during the study are available from the corresponding author upon reasonable request.

\section{Authors' contributions}

QZ, XW and XC constructed the MCAO model, performed hematoxylin and eosin staining, western blot analysis and reverse transcription-quantitative polymerase chain reaction. AC and GZ determined the NFS, the area of cerebral infarction and oxidative stress indicators. YZ and $\mathrm{YH}$ analyzed and interpreted the data. JS revised the manuscript critically for important intellectual content. YZ and QZ designed the study, supervised the research group and gave final approval of the version to be published. The final version of the manuscript has been read and approved by all authors and each author believes that the manuscript represents honest work.

\section{Ethics approval and consent to participate}

All procedures were approved by the Animal Research Ethics Committee, School of Ningxia Medical University (Yinchuan, China).

\section{Consent for publication}

Not applicable.

\section{Competing interests}

The authors declare that they have no competing interests.

\section{References}

1. Writing Group Members; Mozaffarian D, Benjamin EJ, Go AS, Arnett DK, Blaha MJ, Cushman M, Das SR, de Ferranti S, Després JP, et al: Heart disease and stroke statistics-2016 update: A report from the American heart association. Circulation 133: e338-e360, 2016

2. Hua F, Tang H, Wang J, Prunty MC, Hua XD, Sayeed L and Stein DG: TAK-242, an antagonist for Toll-like receptor 4 protects against acute cerebral ischemia/reperfusion injury in mice. J Cereb Blood Flow Metab 35: 536-542, 2015.

3. El Amki M and Wegener S: Improving cerebral blood flow after arterial recanalization: A novel therapeutic strategy in stroke. Int J Mol Sci 18: E2669, 2017.

4. Zhang X, Chen L, Dang X, Liu J, Ito Y and Sun W: Neuroprotective effects of total steroid saponins on cerebral ischemia injuries in an animal model of focal ischemia/reperfusion. Planta Med 80: 637-644, 2014.

5. Melani A, Dettori I, Corti F, Cellai L and Pedata F: Time-course of protection by the selective $\mathrm{A}_{2 \mathrm{~A}}$ receptor antagonist SCH58261 after transient focal cerebral ischemia. Neurol Sci 36: 1441-1448, 2015.

6. Zhang R, Xu M, Wang Y, Xie F, Zhang G and Qin XY: Nrf2-a promising therapeutic target for defensing against oxidative stress in stroke. Mol Neurobiol 54: 6006-6017, 2017.

7. Žitňanová I, Šiarnik P, Kollár B, Chomová M, Pazderová P, Andrezálová L, JeDovilová M, Koňariková K, Laubertová L, Krivošíková $\mathrm{Z}$, et al: Oxidative stress markers and their dynamic changes in patients after acute ischemic stroke. Oxid Med Cell Longev 2016: 9761697, 2016.

8. Adibhatla RM and Hatcher JF: Altered lipid metabolism in brain injury and disorders. Subcell Biochem 49: 241-268, 2008.

9. Guo J, Cheng C, Chen CS, Xing X, Xu G, Feng J and Qin X: Overexpression of Fibulin-5 attenuates ischemia/reperfusion injury after middle cerebral artery occlusion in rats. Mol Neurobiol 53: 3154-3167, 2016.

10. Ashabi G, Khalaj L, Khodagholi F, Goudarzvand M and Sarkaki A: Pre-treatment with metformin activates Nrf2 antioxidant pathways and inhibits inflammatory responses through induction of AMPK after transient global cerebral ischemia. Metab Brain Dis 30: 747-754, 2015.

11. Ding Y, Chen M, Wang M, Li Y and Wen A: Posttreatment with 11-keto- $\beta$-Boswellic acid ameliorates cerebral ischemia reperfusion injury: Nrf2/HO-1 pathway as a potential mechanism. Mol Neurobiol 52: 1430-1439, 2015. 
12. Milanlioglu A, Aslan M, Ozkol H, Cilingir V, Nuri Aydın M and Karadas S: Serum antioxidant enzymes activities and oxidative stress levels in patientswith acute ischemic stroke: Influence on neurological status and outcome. Wien Klin Wochenschr 128: 169-174, 2016.

13. Zhao J, Yu S, Zheng W, Feng G, Luo G, Wang L and Zhao Y: Curcumin improves outcomes and attenuates focal cerebral ischemic injury via antiapoptotic mechanisms in rats. Neurochem Res 35: 374-379, 2010

14. Chen S, Peng H, Rowat A, Gao F, Zhang Z, Wang P, Zhang W, Wang $X$ and $\mathrm{Qu} \mathrm{L}$ : The effect of concentration and duration of normobaric oxygen in reducing caspase- 3 and -9 expression in a rat-model of focal cerebral ischaemia. Brain Res 1618: 205-211, 2015.

15. Wagner DC, Riegelsberger UM, Michalk S, Härtig W, Kranz A and Boltze J: Cleaved caspase-3 expression after experimental stroke exhibits different phenotypes and is predominantly non-apoptotic Brain Res 1381: 237-242, 2011.

16. Endres M, Namura S, Shimizu-Sasamata M, Waeber C, Zhang L, Gómez-Isla T, Hyman BT and Moskowitz MA: Attenuation of delayed neuronal death after mild focal ischemia in mice by inhibition of the caspase family. J Cereb Blood Flow Metab 18: 238-247, 1998.

17. Ma J,Endres M and Moskowitz MA: Synergistic effects of caspase inhibitors and MK-801 in brain injury after transient focal cerebral ischaemia in mice. Br J Pharmacol 124: 756-762, 1998.

18. Sugawara T, Lewén A, Gasche Y, Yu FS and Chan P: Overexpression of SOD1 protects vulnerable motor neurons after spinal cord injury by attenuating mitochondrial cytochrome c release. FASEB J 16: 1997-1999, 2002.

19. Tsang SW and Bian ZX: Anti-fibrotic and Anti-tumorigenic effects of rhein, a natural anthraquinone derivative, in mammalian stellate and carcinoma cells. Phytother Res 29: 407-414, 2015

20. Liu J, Uematsu H, Tsuchida N and Ikeda MA: Essential role of caspase- 8 in p53/p73-dependent apoptosis induced by etoposide in head and neck carcinoma cells. Mol Cancer 10: 95, 2011.

21. Cong XD, Ding MJ, Dai DZ, Wu Y, Zhang Y and Dai Y: ER stress, p66shc, and p-Akt/Akt mediate adjuvant-induced inflammation, which is blunted by argirein, a supermolecule and rhein in rats. Inflammation 35: 1031-1040, 2012.

22. Gao Y, Chen X, Fang L Liu F, Cai R, Peng C and Qi Y: Rhein exerts pro-and anti-inflammatory actions by targeting IKK $\beta$ inhibition in LPS-activated macrophages. Free Radic Biol Med 72: 104-112, 2014.

23. Wang Y, Fan R, Luo J, Tang T, Xing Z, Xia Z, Peng W, Wang W, Lv H, Huang W, et al: An ultra high performance liquid chromatography with tandem mass spectrometry method for plasma and cerebrospinal fluid pharmacokinetics of rhein in patients with traumatic brain injury after administration of rhubarb decoction. J Sep Sci 38: 1100-1108, 2015.

24. Lam BY, Lo AC, Sun X, Luo HW, Chung SK and Sucher NJ: Neuroprotective effects of tanshinones in transient focal cerebral ischemia in mice. Phytomedicine 10: 286-291, 2003

25. Li H, Deng CQ, Chen BY, Zhang SP, Liang Y and Luo XG Total saponins of Panax Notoginseng modulate the expression of caspases and attenuate apoptosis in rats following focal cerebral ischemia-reperfusion. J Ethnopharmacol 121: 412-418, 2009.

26. Zhao Q, Cheng $X$, Wang $X$, Wang J, Zhu Y and Ma X: Neuroprotective effect and mechanism of Mu-Xiang-You-Fang on cerebral ischemia-reperfusion injury in rats. J Ethnopharmacol 192 140-147, 2016.

27. Lian Y, Xie L, Chen M and Chen L: Effects of an astragalus polysaccharide and rhein combination on apoptosis in rats with chronic renal failure. Evid Based Complement Alternat Med 2014: 271862, 2014

28. Genovese T, Mazzon E, Paterniti I, Esposito E, Bramanti P and Cuzzocrea S: Modulation of NADPH oxidase activation in cerebral ischemia/reperfusion injury in rats. Brain Res 1372: 92-102, 2011.

29. Longa EZ, Weinstein PR, Carlson S and Cummins R: Reversible middle cerebral artery occlusion without craniectomy in rats. Stroke 20: 84-91, 1989.

30. Livak KJ and Schmittgen TD: Analysis of relative gene expression data using real-time quantitative PCR and the 2(-Delta Delta C(T)) method. Methods 25: 402-408, 2001

31. Kaushal V and Schlichter LC: Mechanisms of microgliamediated neurotoxicity in a new model of the stroke penumbra. J Neurosci 28: 2221-2230, 2008

32. Browning JD and Horton JD: Molecular mediators of hepatic steatosis and liver injury. J Clin Invest 114: 147-152, 2004.
33. Rosen DR, Siddique T, Patterson D, Figlewicz DA, Sapp P, Hentati A, Donaldson D, Goto J, O'Regan JP, Deng HX, et al: Mutations in $\mathrm{Cu} / \mathrm{Zn}$ superoxide dismutase gene are associated with familial amyotrophic lateral sclerosis. Nature 362: 59-62, 1993.

34. Vakili A, Sharifat S, Akhavan MM and Bandegi AR: Effect of lavender oil (Lavandula angustifolia) on cerebral edema and its possible mechanisms in an experimental model of stroke. Brain Res 1548: 56-62, 2014.

35. Rodrigo R, Fernández-Gajardo R, Gutiérrez R, Matamala JM, Carrasco R, Miranda-Merchak A and Feuerhake W: Oxidative stress and pathophysiology of ischemic stroke: Novel therapeutic opportunities. CNS Neurol Disord Drug Targets 12: 698-714, 2013.

36. Schettler V, Methe H, Staschinsky D, Schuff-Werner P, Müller GA and Wieland E: Review: The oxidant/antioxidant balance during regular low density lipoprotein apheresis. Ther Apher 3: 219-226, 1999.

37. Fulda S, Galluzzi L and Kroemer G: Targeting mitochondria for cancer therapy. Nat Rev Drug Discov 9: 447-464, 2010.

38. Circu ML and Aw TY: Reactive oxygen species, cellular redox systems, and apoptosis. Free Radic Biol Med 48: 749-762, 2010.

39. Carmona-Gutierrez D, Eisenberg T, Büttner S, Meisinger C, Kroemer G and Madeo F: Apoptosis in yeast: Triggers, pathways, subroutines. Cell Death Differ 17: 763-773, 2010.

40. Fuchs Y and Steller H: Programmed cell death in animal development and disease. Cell 147: 742-758, 2011.

41. Zhen YF, Wang GD, Zhu LQ, Tan SP, Zhang FY, Zhou XZ and Wang XD: P53 dependent mitochondrial permeability transition pore opening is required for dexamethasone-induced death of osteoblasts. J Cell Physiol 229: 1475-1483, 2014.

42. Matés JM, Segura JA, Alonso FJ and Márquez J: Intracellular redox status and oxidative stress: Implications for cell proliferation, apoptosis, and carcinogenesis. Arch Toxicol 82: 273-299, 2008.

43. Sugawara T, Noshita N, Lewén A, Gasche Y, Ferrand-Drake M, Fujimura M, Morita-Fujimura Y and Chan PH: Overexpression of copper/zinc superoxide dismutase in transgenic rats protects vulnerable neurons against ischemic damage by blocking the mitochondrial pathway of caspase activation. J Neurosci 22: 209-217, 2002.

44. Fahmi T, Branch D, Nima ZA, Jang DS, Savenka AV, Biris AS and Basnakian AG: Mechanism of graphene-induced cytotoxicity: Role of endonucleases. J Appl Toxicol37: 1325-1332, 2017.

45. Zhou X, Patel D, Sen S, Shanmugam V, Sidawy A, Mishra L and Nguyen BN: Poly-ADP-ribose polymerase inhibition enhances ischemic and diabetic wound healing by promoting angiogenesis. J Vasc Surg 65: 1161-1169, 2017.

46. Broughton BR, Reutens DC and Sobey CG: Apoptotic mechanisms after cerebral ischemia. Stroke 40: e331-e339, 2009.

47. Rami A, Bechmann I and Stehle JH: Exploiting endogenous anti-apoptotic proteins for novel therapeutic strategies in cerebral ischemia. Prog Neurobiol 85: 273-296, 2008

48. Budihardjo I, Oliver H, Lutter M, Luo X and Wang X: Biochemical pathways of caspase activation during apoptosis. Annu Rev Cell Dev Biol 15: 269-290, 1999.

49. Wang X: The expanding role of mitochondria in apoptosis. Genes Dev 15: 2922-2933, 2001

50. Rossé T, Olivier R, Monney L, Rager M, Conus S, Fellay I, Jansen B and Borner C: Bcl-2 prolongs cell survival after BAX-induced release of cytochrome c. Nature 391: 496-499, 1998.

51. Van Delft MF and Huang DC: How the Bcl-2 family of proteins interact to regulate apoptosis. Cell Res 16: 203-213, 2006.

52. Wang GH, Lan R, Zhen XD, Zhang W, Xiang J and Cai DF: An-Gong-Niu-Huang Wan protects against cerebral ischemia induced apoptosis in rats: Up-regulation of $\mathrm{Bcl}-2$ and downregulation of BAX and caspase-3. J Ethnopharmacol 154: $156-162,2014$

53. Zhao P, Zhou R, Zhu XY, Hao YJ, Li N, Wang J, Niu Y, Sun T, $\mathrm{Li}$ YX and Yu JQ: Matrine attenuates focal cerebral ischemic injury by improving antioxidant activity and inhibiting apoptosis in mice. Int J Mol Med 36: 633-644, 2015.

54. Lee SR, Lok J, Rosell A, Kim HY, Murata Y, Atochin D, Huang PL, Wang X, Ayata C, Moskowitz MA and Lo EH: Reduction of hippocampal cell death and proteolytic responses in tissue plasminogen activator knockout mice after transient global cerebral ischemia. Neuroscience 150: 50-57, 2007. 
55. Pérez-Garijo A: When dying is not the end: Apoptotic caspases as drivers of proliferation. Semin Cell Dev Biol: S1084-9521(17)30500-1, 2017.

56. Liu J, Chen Z, Zhang Y, Zhang M, Zhu X, Fan Y, Shi S, Zen K and Liu Z: Rhein protects pancreatic $\beta$-cells from dynamin-related protein-1-mediated mitochondrial fission and cell apoptosis under hyperglycemia. Diabetes 62: 3927-3935, 2013.

57. Liu H, Zhou Y and Tang L: Caffeine induces sustained apoptosis of human gastric cancer cells by activating the caspase $9 /$ caspase 3 signalling pathway. Mol Med Rep 16: 2445-2454, 2017.

58. Topçu Y, Bayram E, Ozbal S, Yiș U, Tuğyan K, Karaoğlu P, Kumral A, Yilmaz O and Kurul SH: Zonisamide attenuates hyperoxia-induced apoptosis in the developing rat brain. Neurol Sci 35: 1769-1775, 2014

59. Rami A, Sims J, Botez G and Winckler J: Spatial resolution of phospholipid scramblase 1 (PLSCR1), caspase-3 activation and DNA-fragmentation in the human hippocampus after cerebral ischemia. Neurochem Int 43: 79-87, 2003.
60. Le DA, Wu Y,Huang Z, Matsushita K, Plesnila N, Augustinack JC, Hyman BT, Yuan J, Kuida K, Flavell RA and Moskowitz MA: Caspase activation and neuroprotection in caspase-3 deficient mice after in vivo cerebral ischemia and in vitro oxygen glucose deprivation. Proc Natl Acad Sci USA 99: 15188-15193, 2002.

61. Wang N, Zhang Y, Wu L, Wang Y, Cao Y, He L, Li X and Zhao J: Puerarin protected the brain from cerebral ischemia injury via astrocyte apoptosis inhibition. Neuropharmacology 79: 282-289, 2014.

This work is licensed under a Creative Commons Attribution-NonCommercial-NoDerivatives 4.0 International (CC BY-NC-ND 4.0) License. 